\title{
Correspondence
}

\section{Position of pre-senior registrars}

\section{Dear Sirs}

I found Professor Copeland's so-called warning letter about post-membership psychiatrists taking locum consultant posts before senior registrar training (Psychiatric Bulletin, September 1990, 14, 566) unsympathetic. Presumably the threat is that applicants for senior registrar posts will be looked on unfavourably if they have had locum consultant experience. I think it unlikely, though, that psychiatric ability and potential decline during locum consultant experience.

The locum consultant situation is obviously of current importance in the College, as evidenced by the notice in the front cover of recent Psychiatric Bulletins, asking retired consultants to write to the College if they are interested in locum consultant work. This intervention may improve standards, but, if effective, will also prevent pre-senior registrars obtaining these posts.

It is essential the College has an understanding view of the position of pre-senior registrars. The College is to be congratulated on obtaining new senior registrar posts through JPAC. Will they be sufficient, though, to ease the bottleneck between general and higher professional training? JCHPT seem to think so, but does anyone know?

I have suggested in College circles that a survey should be undertaken to assess the seriousness of the problem of post-membership registrars. A random sample of candidates who passed the membership (say) a year previously could be followed up, and their success in obtaining a senior registrar post ascertained. I think such a survey under the auspices of JCHPT would be ideal.

I understand the Collegiate Trainees Committee has become pessimistic about the situation of postmembership registrars. I would be willing to organise a survey, as I am concerned about the position of presenior registrars. Many consultant psychiatrists may have found their career progression smooth, but there is not much doubt in my mind that advancement from registrar to senior registrar is now more competitive and undesirable hardship has been produced.

University Department of Psychiatry

Northern General Hospital

Sheffield S5 $7 A U$

\section{Training in psychiatry}

\section{Dear Sirs}

As organisers of the Mersey Region Training Scheme in Psychiatry we read with interest the paper by Martin Davies 'The all Birmingham rotational scheme for training in psychiatry (1984-1989)' (Psychiatric Bulletin, July 1990, 14, 410-412). Our scheme was formed in 1985 for similar reasons to the Birmingham one and has developed in a surprisingly similar way.

Dr Davies is clearly as concerned as we are about the 'bottleneck' in obtaining senior registrar posts. What is not clear from his paper is the length of time trainees in Birmingham spend training in psychiatry before reaching senior registrar status. We consider that the time spent in the registrar grade is less important than the total time spent in training in psychiatry, i.e. time in SHO grade plus time in registrar grade. If the registrars in the Birmingham scheme stay in post for over three-and-a-half years as stated, then trainees may be spending six years in training before obtaining senior registrar posts and this seems to us rather long.

It may be helpful to explain the procedure which we follow in the Mersey region. Our scheme covers both SHO posts and registrar posts and we insist that trainees must pass Part I of the Membership examinations before being considered for appointment to registrar posts. This in effect means that trainees spend 18 months to two years in the SHO grade. Their length of contract as registrar is adjusted to allow each trainee to gain four years training in psychiatry, i.e. if the trainee spends 18 months as SHO, the registrar contract will be for two years six months, but with close monitoring of progress at regular intervals. After four years, promising trainees (this means most of them) may be re-appointed for six to 12 months to allow them time to gain a senior registrar post. In our opinion this is an adequate length of time. After five years a trainee's chances of gaining a senior registrar post are likely to diminish rapidly. Our records from August 1985 to July 1990 show that for 24 trainees leaving the Mersey region training scheme to take up senior registrar posts, their average length of psychiatric training was four years four months.

Fazakerley Hospital

ERIC BiRCHALL

Liverpool $L 97 A L$

The Scott Clinic

JAMES Higgins

Rainhill, Merseyside 